\title{
Interstimulus interval and viewing time effects in monkey list memory
}

\author{
ROBERT G. COOK and ANTHONY A. WRIGHT \\ University of Texas Health Science Center, Houston, Texas \\ and \\ STEPHEN F. SANDS \\ University of Texas, El Paso, Texas
}

\begin{abstract}
Two rhesus monkeys were tested in 6-and 10-item list memory tasks for performance changes as a function of the exposure duration of the list stimuli and the interstimulus interval (ISI) between successive list stimuli. Accuracy increased with longer item exposure duration and tended to decrease with longer ISI duration. Humans, by contrast, typically show increases in accuracy with ISI, a result taken as evidence of rehearsal. The decrease in accuracy for monkeys suggests that they were not using rehearsal processes in these list memory experiments. Further tests in which choice accuracy with predictable ISIs was compared with choice accuracy with unpredictable ISIs also yielded no evidence of rehearsal by the monkeys. This apparent absence of rehearsal mechanisms in monkeys, in situations also shown to support human rehearsal, is discussed as a potential difference in the visual working memory processes of the two species.
\end{abstract}

Humans regularly engage in rehearsal. Indeed it is difficult to imagine a day going by without our rehearsing something, whether it be telephone numbers, addresses, shopping lists, or names of new acquaintances. Although rehearsal often involves language, this apparently is not a necessary requirement; rehearsal can occur with pictorial stimuli in humans (Watkins, Peynircioglu, \& Brems, 1984). In this article, rehearsal will be considered as a subject-controlled, memory-based repetition of to-be-remembered material (cf. Johnson, 1980; Watkins \& Peynircioglu, 1982). This relatively broad view of rehearsal includes both the overt and covert rehearsal of either visual or verbal materials. When considered thus, rehearsal does not depend on language, and this opens up the possibility that other animals may also have rehearsal-like processes. Procedures involving our human capabilities for language and speech have been valuable and frequently used in the study of rehearsal (see, e.g., Dark \& Loftus, 1976; Rundus, 1971; Rundus \& Atkinson, 1970; Modigliani \& Hedges, 1987), but obviously they cannot be used in examining this question in other animals.

During the past decade, the interstimulus-interval (ISI) or blank-time procedure has been developed as a promising means of studying animal rehearsal. Rehearsal in humans is identified in this procedure through the increased accuracy that is observed when the ISIs between the items of a to-be-remembered list or sequence are lengthened.

This research was supported by Grant MH 35202 to A. A. Wright and by Postdoctoral Fellowship EY 05653 to R. G. Cook. Reprint requests should be sent to Robert G. Cook, who is now in the Department of Psychology, Paige Hall, Tufts University, Medford, MA 02155.
For example, Intraub (1980) presented subjects with sequences of 16 pictures at different ISIs and then tested item recognition. Subjects presented with pictures for $110 \mathrm{msec}$ and no ISI performed at only $59 \%$ accuracy, but as the ISI was lengthened to $385 \mathrm{msec}, 620 \mathrm{msec}$, $1,390 \mathrm{msec}$, and finally $4,890 \mathrm{msec}$, performance increased to $71 \%, 78 \%, 91 \%$, and $92 \%$, respectively. ${ }^{1}$ Performance in the 4,890-msec ISI condition (viewing time, $110 \mathrm{msec}$ ) was as accurate as it was when each item was visible for $5 \mathrm{sec}$. This increase in accuracy with longer ISIs will be referred to as the ISI effect in the present article.

The ISI effect is robust, and it has been repeatedly demonstrated with human subjects (Hines \& Smith, 1977; Intraub, 1980; Lichtenstein \& Keren, 1979; Lutz \& Scheirer, 1974; Proctor, 1983; Tversky \& Sherman, 1975; Weaver, 1974; Weaver \& Stanny, 1978). As is expected of a rehearsal mechanism, it is under the subject's voluntary control (Graefe \& Watkins, 1980; Watkins \& Graefe, 1981), and it is disrupted if there is uncertainty about the length of the ISI interval (Avons \& Phillips, 1980; Phillips \& Christie, 1977; Proctor, 1983; Shaffer \& Shiffrin, 1972). Furthermore, ISI effects occur with both verbal and pictorial materials (Watkins et al., 1984).

Consequently, the ISI procedure is ideal for the investigation of rehearsal in animals. It is an objective procedure, requiring only the ability to later recognize serially presented "lists" of to-be-remembered picture items, a task that monkeys easily perform (see, e.g., Sands \& Wright, 1980a). Thus far, the ISI procedure has been used in two experiments to investigate the question of whether monkeys rehearse or not (Roberts \& Kraemer, 1984; Sands, Urcuioli, Wright, \& Santiago, 1984). 
Roberts and Kraemer (1984) tested 3 squirrel monkeys in a matching-to-sample task with 3-item lists of pictures. They found that matching accuracy was reduced when list items were separated by a 6-sec ISI, as opposed to a 0-sec ISI. They concluded that nonhuman primates may not continue to process picture information in the absence of the to-be-remembered picture.

Sands et al. (1984) tested 2 rhesus monkeys in a serial probe recognition task (SPR) by using variable list lengths of 2-10 list items and two ISIs $(.08$ and $1 \mathrm{sec})$. The adolescent monkey (Felix) showed no increase in accuracy when tested with the longer ISI, while the older, more experienced, monkey (Oscar) showed a 7\% increase. Sands et al. cautiously suggested that adult monkeys may be able to engage in limited rehearsal, whereas younger animals may not. Taken together, however, these experiments suggested that 4 of the 5 monkeys tested were not as readily adept as humans in rehearsing visual list items in their absence.

This conclusion contrasts sharply with most of the other recent experimental results regarding list memory in monkeys, in which it has been found that the visual working memory processes of humans and monkeys exhibit very similar properties, and by implication, similar mechanisms (Herzog, Grant, \& Roberts, 1977; Jitsumori, Wright, \& Shyan, 1989; Roberts \& Kraemer, 1981, 1984; Sands \& Wright, 1980a, 1980b, 1982; Wright, Santiago, \& Sands, 1984; Wright, Santiago, Sands, Kendrick, \& Cook, 1985). If so, this absence of rehearsal-like processes in monkeys portends an important qualitative difference in the visual working memory processes of the two species.

As has frequently been pointed out in the history of comparative psychology, however, an absence of evidence does not constitute unequivocal evidence of absence. Thus, because of the mixed results of Sands et al. (1984) and the limited range of conditions over which the effects of ISI have previously been examined, any conclusion about the absence of rehearsal processes in monkeys must be provisional. Consequently, in order to increase our confidence about this potentially important difference between the memory processes of monkeys and of humans, we wanted to extend and clarify the equivocal results for rhesus monkeys reported by Sands et al. (1984).

In the present experiments, we investigated list rehearsal by using the ISI procedure with the 2 rhesus monkeys tested by Sands et al. (1984). We had several objectives. The first was to examine the time course of the ISI effect in our monkeys more completely and precisely. The second was to broaden the range and type of conditions used in testing for the presence of rehearsal-like processes in monkeys; toward this end, we tested the monkeys with 6- and 10-item lists and with predictable and unpredictable ISIs. The third was to directly compare human and monkey ISI performance in identical testing conditions. We wanted to be sure that our testing procedures could indeed produce the standard ISI effect in humans. Toward this end, some of the tests were identical in all important respects to a companion ISI experiment used to test human subjects (Wright et al., 1990).

In Experiment 1, the monkeys were tested for the ISI effect with 6-item and 10-item lists over a range of .084 sec. In Experiment 2, the monkeys were tested with a different experimental strategy for detecting the presence of rehearsal processes in monkeys. The strategy was similar to one developed and used previously for testing rehearsal in humans by using predictable and unpredictable arrangements of the ISIs (Proctor, 1983).

\section{EXPERIMENT 1}

Experiment 1 involved the SPR list memory procedure. In this SPR task, a list of pictures was presented sequentially to the subject. After the list, a test or probe item was presented. The subject then moved a response lever to indicate whether the probe item was in the list (a same response) or not in the list (a different response). Correct choices were rewarded with food or juice.

In this list memory experiment, monkey perceptual encoding processes, as measured by changes in accuracy as a function of item viewing time, were directly compared with potential rehearsal processes, as measured by changes in accuracy as a function of ISI. Five durations $(.08, .5,1,2$, and $4 \mathrm{sec})$ of viewing time and ISI were varied independently, using lists that were 6 or 10 items in length. The 6-item list test phase was identical to a previous experiment done with human subjects (Wright et al., 1990), which allowed the comparison of the two species in the same procedure. A test with 10-item lists was also conducted in order to increase memory load and create conditions in which the use of rehearsal by the monkeys might be more advantageous for maintaining high levels of accuracy.

\section{Method}

\section{Subjects}

The subjects were 2 highly experienced rhesus monkeys (Macaca mulatta), Oscar and Felix, previously trained in the SPR task (Sands et al., 1984; Sands \& Wright, 1980a, 1980b, 1982; Wright et al., 1984). The monkeys had restricted access to food and water for $18 \mathrm{~h}$ before each session. Supplemental food and water were given approximately $6 \mathrm{~h}$ after each session. Sessions were conducted 5 days per week.

\section{Apparatus}

The monkeys were tested unrestrained in an aluminum primate cage $(62 \times 62 \times 92 \mathrm{~cm})$. The animals indicated their choices with a three-position $T$ response lever located at the front center of the cage. Two high-speed Super 8-mm film projectors (Bessler Cue/See) projected the stimuli onto the display screens. Two rear-projected display screens, $(18 \mathrm{~cm}$ wide $\times 12 \mathrm{~cm}$ high) arranged one above the other and $16 \mathrm{~cm}$ apart (center to center), were mounted onto a matte-black plywood panel $(77 \mathrm{~cm}$ wide $\times 182 \mathrm{~cm}$ high) located $61 \mathrm{~cm}$ in front of the cage. The projectors were located $60 \mathrm{~cm}$ behind the screens. Sequences of picture stimuli (described below) were made by filming $35-\mathrm{mm}$ slides with a Super $8-\mathrm{mm}$ movie camera. The pictures in the film sequence alternated with dark frames, which functioned as shutters controlling stimulus onset and 
offset. These stimulus sequences could be shown at a peak rate of one frame every $.08 \pm .01 \mathrm{sec}$ (calibrated directly from the display screens with a photo-sensitive diode and oscilloscope). A microcomputer (Cromemco Z-2D) controlled and recorded all experimental events.

\section{Procedure}

Serial probe recognition task. Trials began with a ready signal (5-Hz pulse rate clicker). The clicker was presented until the monkey pressed the lever down, beginning the presentation of the list items. The list items appeared sequentially on the upper display screen (details of viewing time and ISI manipulations are given below). Following the last list item, a 1-sec retention interval preceded the presentation of the probe test item on the lower display screen. The probe item remained on for $4 \mathrm{sec}$ or until a right- or left-lever response was recorded. Moving the lever to the right indicated a same response, and moving the lever to the left indicated a different response. A same response was correct when the probe item matched any one of the list items. A different response was correct when the probe item was not in the list. Correct responses were rewarded with either a 1-g banana pellet (Noyes) or a 5-cc squirt of orange drink (Tang), with the particular reward determined pseudorandomly on each trial. Incorrect responses produced a 10-sec time-out, accompanied by the illumination of a bright overhead houselight. A 4-sec interval separated trials.

Three 192-trial film sequences were made for the 6-item list tests. Each sequence consisted of 96 same trials and 96 different trials. Each of these trials had a list length of 6 items. The list and probe items of each trial were selected from a set of 32 color pictures of natural and man-made objects (landscapes, flowers, people, fruits, animals, toys, keys, watches, trees, boats, and cars). Within each film sequence, each item appeared 36 times as a list item and 6 times as a probe item ( 3 times on same trials and 3 times on different trials). The ordering of the same and different trials and the pictures constituting these trials were randomized in each sequence. The serial positions tested and the serial positions of each item were equated to the degree permitted by the constraints of the procedure.

Preparatory training for fast list-presentation rates. The monkeys had had considerable previous experience in the SPR task and needed no training in the basic task. Because the planned rates for presenting list stimuli were faster than those to which the monkeys were accustomed, the list-presentation rate was gradually increased prior to the experiments. This rate-habituation training lasted $\mathbf{5 0}$ sessions and employed all three 6-item film sequences in a pseudorandom order across sessions.

Rate-habituation training began with an item viewing time of $2 \mathrm{sec}$ and an ISI of $.08 \mathrm{sec}$. The viewing time per item was then gradually reduced across sessions. The viewing time for each monkey's daily session was adjusted to keep overall accuracy at $70 \%$ correct or better. At the end of training, the monkeys were consistently above $70 \%$ correct with a .08 -sec viewing time per item and a .08-sec ISI between items. In the next 16 training sessions, ISIs of .08 and $1 \mathrm{sec}$ were used with a viewing time of $.08 \mathrm{sec}$. Following this preparatory training, the main experiments reported below were begun. Because one film sequence advanced unreliably, only two of the three 6-item film sequences were subsequently used.

Viewing time and ISI testing with 6-item lists. Five viewing times and ISIs were tested: $.08, .5,1,2$, and $4 \mathrm{sec}$. In each session, one of these five durations was pseudorandomly selected and tested in conjunction with a $.08-\mathrm{sec}$ duration. These two durations were then pseudorandomly assigned as the viewing time and ISI for the first half of the 192 daily trials, and then reversed for the second half of the trials. For example, during testing with the 1-sec duration as a viewing time first in a session, the first 96 trials had a viewing time of $1 \mathrm{sec}$ and an ISI of $.08 \mathrm{sec}$, whereas the last 96 trials had an ISI of $1 \mathrm{sec}$ and a viewing time of $.08 \mathrm{sec}$. This equated the total list-presentation time for every trial in a session. Whether viewing time or ISI was held at $.08 \mathrm{sec}$ during the first 96 trials was counterbalanced across blocks. Each of the five durations was tested twice, once with each film sequence, over 10 daily sessions.

Item-memorization tests. Since slide projectors could not be used with the fast presentation rates employed in this experiment, it was impractical to vary the sequences and trial composition of the pictures on a regular basis. It seemed unlikely that the monkeys could have learned anything about the order of the trials and stimuli, however, given the comparatively small set of pictures (32) and their extensive repetition over the large number of trials (384). Nevertheless, the possibility that responses to individual pictures had been memorized or that the sequence of trials had been memorized was examined. This was done with special tests in which the relational information provided by the list and probe items was eliminated, thereby leaving only memorized responses to guide performance. In other circumstances, these tests have reliably detected such memorization (Wright, Cook, \& Kendrick, 1989). In the listonly test, the probe items for each trial were replaced with a blank white illumination of the lower screen, whereas in the probe-only test, the list items were replaced with a blank white illumination of the upper viewing screen (see Wright et al., 1989, for details). Trials were otherwise normally conducted, except for the use of these blank replacement "items." The six list stimuli were displayed for $1 \mathrm{sec}$ each, with an ISI of $.08 \mathrm{sec}$ between items. These tests were conducted at the end of the 6-item list experiments, to examine the most frequently seen of the two film sequences ( 54 total sessions at that point). Since the earliest trials of a sequence were the most likely to be memorized, only the first 96 trials were examined in order to provide the most sensitive test. Testing was conducted over 4 days. Day 1 consisted of a 96-trial baseline session with both list and probe items presented; on Day 2, we tested for control by probe test items (probe-only test); on Day 3 , we tested for control by list items (list-only test); and on Day 4 , we tested with a second 96-trial baseline session.

These tests showed that the monkeys had not memorized correct responses to specific items of the film sequence. Average accuracy for the 2 monkeys on the baseline tests was $69 \%$ correct. Average accuracy for the 2 monkeys on the probe-only test was $54.5 \%$ (Felix, $55 \%$; Oscar, $54 \%$ ), and on the list-only test, it was $52.5 \%$ (Felix, $47 \%$; Oscar, $58 \%$ )-values not different from those expected by chance. This conclusion was further supported by the immediate transfer of the monkeys' SPR performance upon introduction of the 10-item list sequences, which were composed from an entirely new set of 32 pictures.

Viewing time and ISI testing with 10-item lists. In the 10-item phase of the experiment, the number of items in the list was increased to 10 . Two new film sequences containing 128 trials (64 same and 64 different trials) were made from a completely new set of 32 color pictures of natural and man-made objects. Each item was presented 40 times as a list item and 4 times as a probe item ( 2 same and 2 different trials). The same durations were tested (.08, $.5,1,2$, and $4 \mathrm{sec}$ ), and the organization of each session with regard to the testing of viewing time and ISI was the same as in the 6-item test. The experiment consisted of four five-session blocks. Each duration was tested once in each block, with the film sequences tested equally often with all durations over the four blocks.

\section{Results}

Testing with 6-item lists. Mean choice accuracy as a function of viewing time and ISI for the 6-item list test is displayed in Figure 1. Overall, increases in the length of the ISI decreased choice accuracy, whereas increases in the length of the viewing time increased choice accuracy. In a three-way analysis of variance (ANOVA), the percentage correct from each monkey's test sessions 


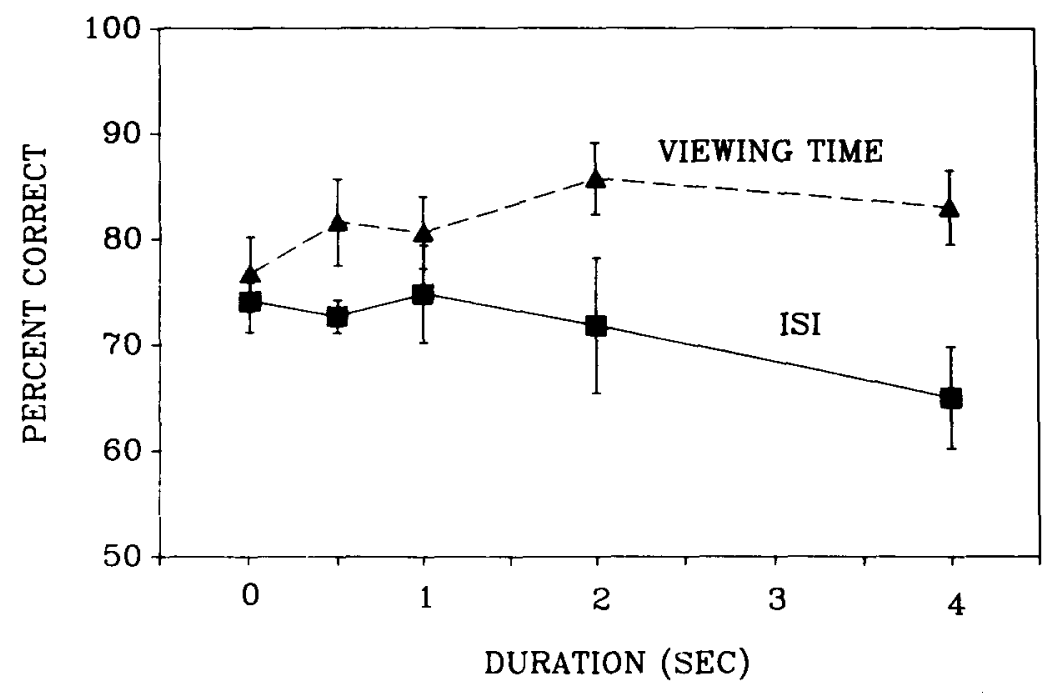

Figure 1. Mean percentage correct for both monkeys as a function of viewing time and ISI duration when tested with 6-item lists. Error bars represent the standard error of the means.

was used to examine the influence of interval type (viewing time vs. ISI), duration, and subject. Oscar was more accurate than Felix at the SPR task (82.5\% vs. $70.7 \%$ ), and this was confirmed by a significant main effect of subject $[F(1,20)=78.4, p<.001]$. More importantly, no significant higher order interactions were found between subject and the duration, interval type, or duration $\times$ interval type terms of this analysis, indicating that both monkeys responded similarly to the manipulations.

There was a significant interaction $[F(4,20)=4.2, p<$ .013 ] between interval type and duration. As can be seen in Figure 1, this interaction appears to be due to the increased accuracy with longer viewing times and the decreased accuracy with longer ISIs. Linear and quadratic trend analyses (Keppel, 1973) were conducted separately on the viewing time and ISI data in order to examine their form more closely. These analyses for trends showed that the changes in accuracy across duration for viewing time were significantly linear $[F(1,10)=8.5, p<.02]$. The quadratic test for the viewing time function was also close to significance $[F(1,10)=4.2, p=.066]$. The latter result appears to be due to the slight reduction in accuracy that occurred with the 4-sec viewing time. The trend analyses of the ISI function also revealed a significantly linear trend across durations $[F(1,10)=5.8, p<.04]$. These separate linear trends reflect the opposing influences that longer viewing time and ISI had on choice accuracy. The nonequivalent effects of viewing time and ISI on list memory are further indicated by the increasing difference scores between these conditions over the five durations: $2.6 \%$, $8.9 \%, 5.7 \%, 13.8 \%$, and $18.8 \%$, respectively (scores generated by subtracting accuracy between the comparable viewing time and ISI conditions of each session).

We also examined choice accuracy as a function of an item's serial position within the list. A four-way ANOVA (serial position of probe within the list $x$ duration $x$ interval type $\times$ subject) was used to compare the responding on same trials (serial position effects cannot be evaluated for different trials). Again the 2 monkeys performed in a similar manner. The only significant interaction with subjects occurred with list serial position [serial position $\times$ subject, $F(5,194)=2.84, p<.01]$. This interaction was due to Felix's being more accurate than Oscar in tests of later list items than in tests of earlier items.

Of more interest was the significant interaction between serial position and duration $[F(20,194)=1.68, p=$ .038]. This interaction is displayed in Figure 2 . At the .08 -sec duration, list serial position had apparently no influence on responding. At the $.5-\mathrm{sec}$ duration, the serial position function was U-shaped. At the three longer durations $(1,2$, and $4 \mathrm{sec})$, same responding monotonically increased with successive serial position in the list.

Linear and quadratic trend analyses were conducted to evaluate the form of these serial position functions. In these analyses, combined data from the viewing time and ISI conditions were used, since there were no significant interactions involving these conditions in the prior ANOVA. There were no systematic trends in responding across serial position at the .08 -sec duration $[F \mathrm{~s}(1,36)<1]$. The $\mathrm{U}$-shaped nature of the serial position function for the .5 -sec condition was confirmed by a significant quadratic trend component $[F(1,36)=7.0, p<.01]$. For the three longer durations, the increasing percentage of same responses across serial positions was confirmed by the significant linear changes for all three durations $[F(1,36)$ $=18.9, p<.001$, for $1 \mathrm{sec} ; F(1,36)=17.1, p<.002$, for $2 \mathrm{sec} ; F(1,36)=5.0, p<.03$, for $4 \mathrm{sec}]$.

Testing with 10-item lists. Mean choice accuracy as a function of viewing time and ISI for the 10-item list test is displayed in Figure 3. The outcome of this test was very 


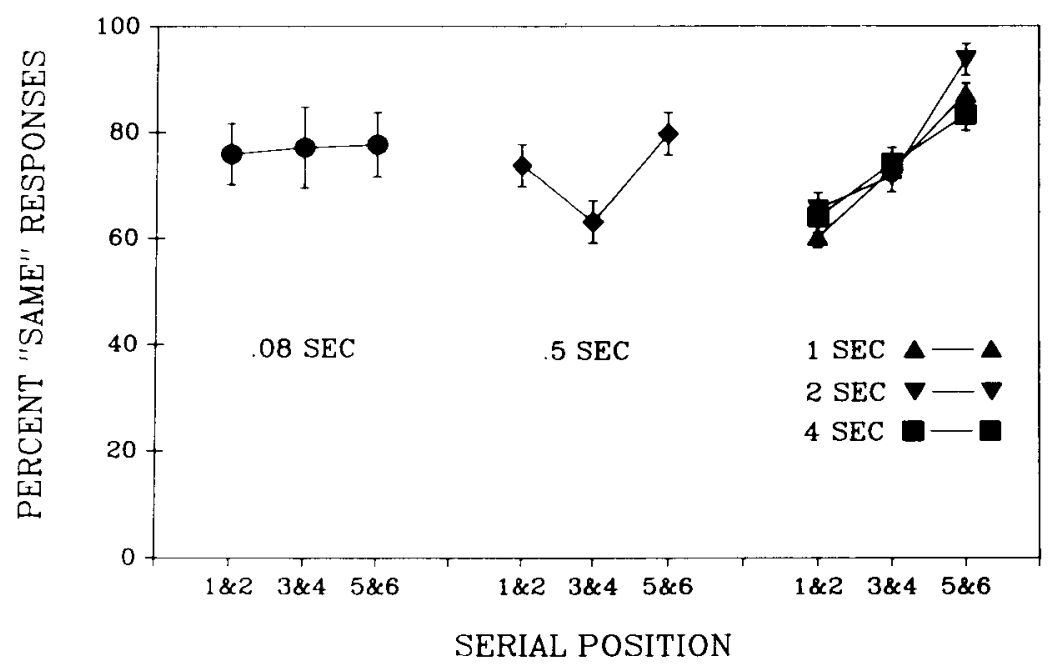

Figure 2. Mean percentage of same responses for both monkeys as a function of list serial position for the 6-item list phase. Conditions are grouped according to trend analyses described in text.

similar to that observed with 6-item lists. Increasing viewing time improved choice accuracy, whereas increasing ISI reduced choice accuracy. A three-way ANOVA of choice accuracy, with the factors interval type (viewing time vs. ISI) $\times$ duration $\times$ subject, yielded no significant interactions between the subject term and the experimental manipulations. Once again, both monkeys responded in a similar manner during the tests, although Oscar continued to be more accurate than Felix $[F(1,60)$ $=4.7, p<.04]$.

Interval type significantly influenced choice accuracy $[F(1,60)=25.2, p<.001]$, with the viewing time conditions $(71.6 \%)$ supporting higher accuracy than that sup- ported by the ISI conditions $(64.2 \%)$. The interaction between interval type and duration was not significant in the 10 -item test $[F(4,60)=1.14, p>.30]$. Further tests suggested, however, that the significantly higher accuracy in the viewing time condition was confined to the longer durations. Separate tests on each duration revealed no significant differences in accuracy between the viewing time and ISI conditions at the two shortest durations $[.08 \mathrm{sec}$, $F(1,12)=1.4 ; .5 \mathrm{sec}, F(1,12)=1.0$; all $p \mathrm{~s}>.25]$, but at the three longest durations, the monkeys were significantly more accurate in the viewing time conditions $[1 \mathrm{sec}$, $F(1,12)=5.7 ; 2 \mathrm{sec}, F(1,12)=20.4 ; 4 \mathrm{sec}, F(1,12)=$ 9.8; all $p \mathrm{~s}<.05]$. The increasing difference scores for

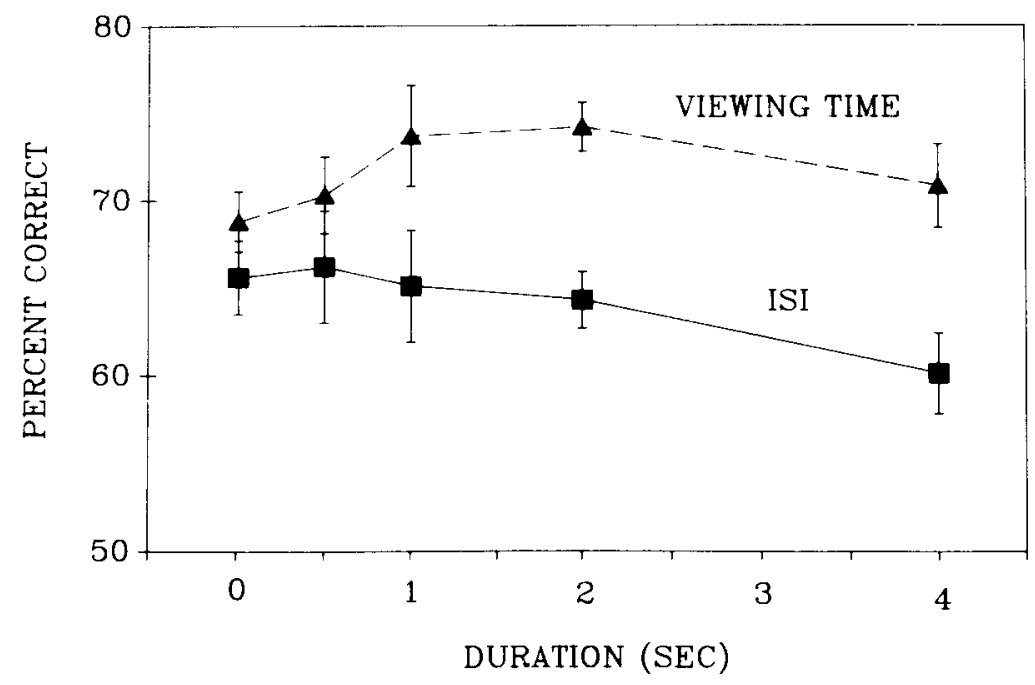

Figure 3. Mean percentage correct for both monkeys as a function of viewing time and ISI duration when tested with 10-item lists. Error bars represent the standard error of the means. 


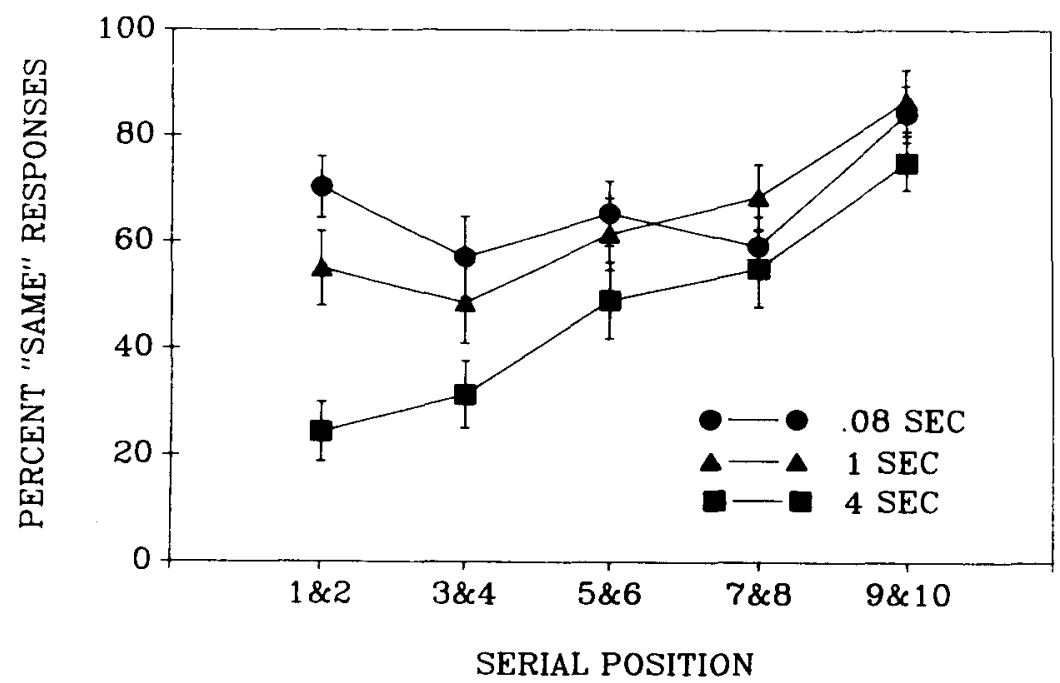

Figure 4. Mean percentage of same responses for both monkeys as a function of list serial position for the 10-item list phase for short, intermediate, and long durations. Error bars represent the standard error of the means.

the two conditions also suggests a divergence with longer durations $(3.2 \%, 4.1 \%, 8.5 \%, 9.8 \%$, and $10.7 \%$, respectively).

Again, trend analyses were conducted separately on the viewing time and ISI data to examine their exact form. These analyses yielded a significantly linear trend in accuracy across the first four viewing times $[F(1,24)=5.2$, $p<.03]$. The quadratic test for all five durations neared significance $[F(1,30)=2.9, p=.096]$. The trend analyses of the ISI function revealed no significant trend across duration [linear contrast, $F(1,30)=2.4, p=.12$ ]

The serial position functions from the 10-item list test are shown in Figure 4. Responses were combined into five serial position pairs ( 1 and 2,3 and 4, 5 and 6,7 and 8,9 and 10) for analyses and are displayed only for the short (.08-sec), intermediate (1-sec), and long (4-sec) durations. The probability of responding same decreased significantly more quickly for early list items than for later items across duration, as was confirmed by a significant duration $\times$ serial position interaction $[F(16,356)=1.8$, $p<.04]$ in a four-way ANOVA (serial position $\times$ duration $\times$ interval type $\times$ subjects). The only other reliable interaction with serial position occurred with subjects $[F(4,356)=4.6, p<.01]$. As with the 6-item lists, this was again due to Felix's more pronounced recency effect, but otherwise the subjects term did not interact with any other factor.

Trend analyses [dfs $F(1,74)$, level of significance set at $p<.05$ ] revealed a significant quadratic component for the .08-sec duration. For the 1-sec condition, a significant linear component was revealed and the quadratic component approached significance $(p<.08)$. For the 2 - and 4-sec durations, only the linear component was significant. Note also that the percentage of same responses drops below $50 \%$ for the earliest items during the 4-sec duration conditions. This suggests that the monkeys had completely forgotten these items, and that they responded to probes of these early list items as if they constituted different trials.

Combined analyses of the 6- and 10-item tests. Because the 6-item and 10-item testing procedures were alike and the pattern of results similar, we also ran an analysis of the two sets of data combined. The number of observations from each experiment were equated for this analysis by regrouping the four blocks of the 10-item test into two. A four-way ANOVA (interval type $x$ duration $x$ list length $X$ subject) revealed a significant interaction of interval type and duration $[F(4,57)=4.3, p<.005]$. Viewing time increased accuracy $[F(4,24)=2.88, p<$ $.044]$, whereas ISI decreased accuracy $[F(4,24)=3.3$, $p<.026$ ]. $T$ tests in which all observations from both tests were used to compare accuracy in the .08 -sec condition with accuracy in the 4-sec condition showed that each monkey's accuracy was significantly poorer in the longer ISI condition (Felix, $t(5)=2.8, p<.05$; Oscar, $t(5)=2.7, p=.05)$. Accuracy was higher with 6-item lists than with 10 -items $[F(1,57)=78.9, p<.001]$, and Oscar was more accurate than Felix $[F(1,57)=59.1$, $p<.001]$.

\section{Discussion}

In consistency with results from human subjects, the monkeys responded more accurately as the viewing time for the list items increased. Contrary to human subjects, the monkeys generally responded less accurately as the ISI between the list items was lengthened. The absence of any improvement in accuracy as ISI increased argues against the idea that the monkeys were rehearsing or further encoding list information during the time between items. The results instead suggest that the encoding of list 
items occurred only when the stimuli were present and stopped when they were removed (see also Roberts \& Kraemer, 1984). During the ISIs, forgetting of the items becomes a factor, especially for those presented early in the list, and it results in lowered performance with long ISIs.

The integration of the present ISI results with those previously reported (Roberts \& Kraemer, 1984; Sands et al., 1984) suggests that the effects of ISI on monkey list memory are best summarized as follows: ISIs of $1 \mathrm{sec}$ or less have little or no detectable influence on accuracy, whereas ISIs of $1 \mathrm{sec}$ or longer have a detrimental influence on list memory in monkeys. Thus, the moderately contrasting results of Sands et al. (1984) and Roberts and Kraemer (1984) were apparently due to the range of values each tested. In these current tests, the monkeys tested by Sands et al. (1984) showed little effect over the ISI durations most similar to those of their previous test, but when they were tested with longer ISIs, their accuracy declined, like that of Roberts and Kraemer's monkeys.

In the 6- and 10-item list phases, the 32 stimuli of each test were presented many times within each daily session. Such high rates of item repetition tend to create considerable proactive interference (Wright, Urcuioli, \& Sands, 1986). We thought that perhaps this buildup of proactive interference over trials might have made the rehearsal of the current trial's items eventually too difficult. As a consequence, we briefly conducted a further test with a film sequence in which the list stimuli were repeated only twice within each session. Such conditions should have reduced proactive interference (Overman \& Doty, 1980; Sands \& Wright, 1980a, 1980b; Wright et al., 1986) and thereby might have allowed the monkeys to benefit from ISI rehearsal more easily. The results with this list were similar to those found with the 6-and 10-item lists. There was no benefit of increasing ISI, and the monkeys were significantly more accurate in the longer viewing time conditions.

In summary, Experiment 1 expands and augments the results of Sands et al., (1984) and clarifies their relation to those of Roberts and Kraemer (1984). We found that in testing conditions designed to detect and promote rehearsal, neither of our 2 monkeys, including 1 previously suspected of rehearsing in the SPR task, demonstrated any positive benefit of ISI.

\section{EXPERIMENT 2}

The ISI procedure appears to consistently fail in providing evidence of rehearsal-like processes in nonhuman primates. The force of this conclusion is increased by the growing number and range of conditions that have failed to yield any positive ISI effects in monkeys. As a consequence, in Experiment 2 we tried a new strategy in a continued effort to detect rehearsal-like processes in monkeys.

Proctor $(1983,1985)$ has presented evidence that humans abandon their poststimulus rehearsal strategies when tested with ISIs of inconsistent or unpredictable lengths.
He conjectured that the rehearsal of old items and the encoding of unpredictably presented new items interfere with one another, and that, as a consequence, human subjects choose not to rehearse item information when ISIs are unpredictable.

Likewise, monkeys might also encounter interference between the encoding of unpredictably timed list stimuli and their subsequent rehearsal. If so, and if the monkeys were capable of some degree of rehearsal during evenly spaced ISIs, choice accuracy should be reduced for lists presented with variable and unpredictable ISIs in comparison with lists having uniform and predictable ISIs. If, on the other hand, monkeys were not rehearsing list items, the arrangement of the ISIs should have little impact on accuracy.

In Experiment 2, we therefore compared two list presentation conditions differing in the relative predictability of their ISIs. In the unpredictable or random condition, five different ISIs $(.08, .5,1,2$, and $4 \mathrm{sec})$ were inserted at random among the six items of each trial. The result of this arrangement of the ISIs was an irregular, "herky jerky" paced presentation of the list items that changed with every trial. In the predictable or uniform condition, the average of these five durations $(1.516 \mathrm{sec})$ separated the list items. This uniform interval produced an evenly paced presentation of the list items.

\section{Method}

Subjects and Apparatus

The subjects, apparatus, and stimuli were the same as those for the 6-item list tests in Experiment 1.

\section{Procedure}

Each test session consisted of 192 trials. The viewing time for each of the six list items was $.08 \mathrm{sec}$. All other parameters were the same as in Experiment 1, except for the arrangement of the ISIs. In the uniform presentation condition, the items of the list were separated by $1.516 \mathrm{sec}$. In the random presentation condition, five different ISIs were used to separate the items of each list: $.08, .5$, 1,2 , and $4 \mathrm{sec}$. These five durations were randomly inserted among the six list items. The ordering of these durations within a list was randomized for every trial.

Each session was divided into two halves. In the first 96 trials, one type of ISI presentation condition was tested; in the remaining 96 trials, the other condition was tested. The order in which the two conditions were tested alternated daily. One of the 6-item film sequences of Experiment 1 was used for the 10 sessions of Experiment 2 .

\section{Results}

Overall choice accuracy in the random presentation condition was virtually identical to that in the uniform presentation condition. The means for each condition and monkey are presented in Table 1. A two-way ANOVA with presentation condition (random vs. uniform) and subject as factors was carried out on accuracy scores for each of the 10 test sessions; there was neither a significant effect of presentation condition nor an interaction with subjects. Oscar was more accurate overall than Felix $[F(1,36)$ $=15, p<.001]$. Additional $t$ tests in which accuracy 
Table 1

Percentage Correct for Uniform and Random Conditions in Experiment 2

\begin{tabular}{lcc} 
& Random & Uniform \\
\hline Oscar & 69.5 & 73.5 \\
Felix & 65.5 & 64.1 \\
$M$ & 67.5 & 68.8 \\
\hline
\end{tabular}

on the random list was compared with accuracy on the uniform list for each individual monkey also revealed no significant differences between the two conditions.

\section{Discussion}

In Experiment 2, unpredictable ISIs did not reduce accuracy, relative to predictable ISIs. These results further argue that monkeys do not rehearse list items during ISIs. The presence of such rehearsal processes would have been indicated by poorer accuracy in the random ISI condition, since it presumably prevents or disrupts such processes (Proctor, 1983, 1985). Instead the monkeys immediately transferred to the random ISI condition upon its introduction and showed no measurable decrement in accuracy in this condition. Considering the 10 years of SPR training and testing that these monkeys had previously received with orderly and evenly spaced list presentation, the present results are even more remarkable.

Watkins (1985), in reaction to Proctor's idea, has argued that humans can redistribute their rehearsal efforts to long ISIs in order to optimize list processing when faced with unpredictable ISIs. Such a mechanism could effectively reduce any difference between random and uniform presentation in humans. Such an explanation for the equivalence of random and uniform conditions in the present experiment, however, requires not only that monkeys rehearse during ISIs, but also that they can control and redis- tribute this rehearsal. In the attempt to account for equal levels of accuracy in the present experiment, it seems simpler to assume the absence of any rehearsal processes in our animals.

\section{GENERAL DISCUSSION}

Experiments 1 and 2 provide converging evidence that rhesus monkeys do not engage in the rehearsal of sequentially presented pictorial items. In Experiment 1, accuracy increased with increased viewing time; but unlike humans', the monkeys' accuracy did not improve, and generally decreased, with longer ISIs. This pattern of results strongly suggests that list encoding processes operate only during stimulus exposure. In Experiment 2, there was no reduction in accuracy when unpredictable ISIs separated the list items, further supporting the hypothesis that rehearsal-like processes were not used in these experiments. Both results are different from those obtained with humans. Consequently, these results suggest an important qualitative difference in the visual working memory mechanisms of the two species.

This differential effect of ISI in monkeys and humans can be compared even more directly. Wright et al. (1990) have demonstrated positive ISI in humans tested with the same stimuli, list length, and sequence of trials used for the monkeys in the 6-item test of this article (a few procedural differences existed; the human subjects rested the response lever on their laps, were instructed on its manipulation, and were rewarded with a tone for correct responses). Figure 5 illustrates the ISI results from their human subjects and from our monkeys in the identical ISI conditions $(.08,1$, and $4 \mathrm{sec})$ tested with 6 -item lists. The humans demonstrated the positive processing benefits of longer ISIs, showing that these procedures and stimuli can indeed produce a robust ISI effect in humans. It is im-

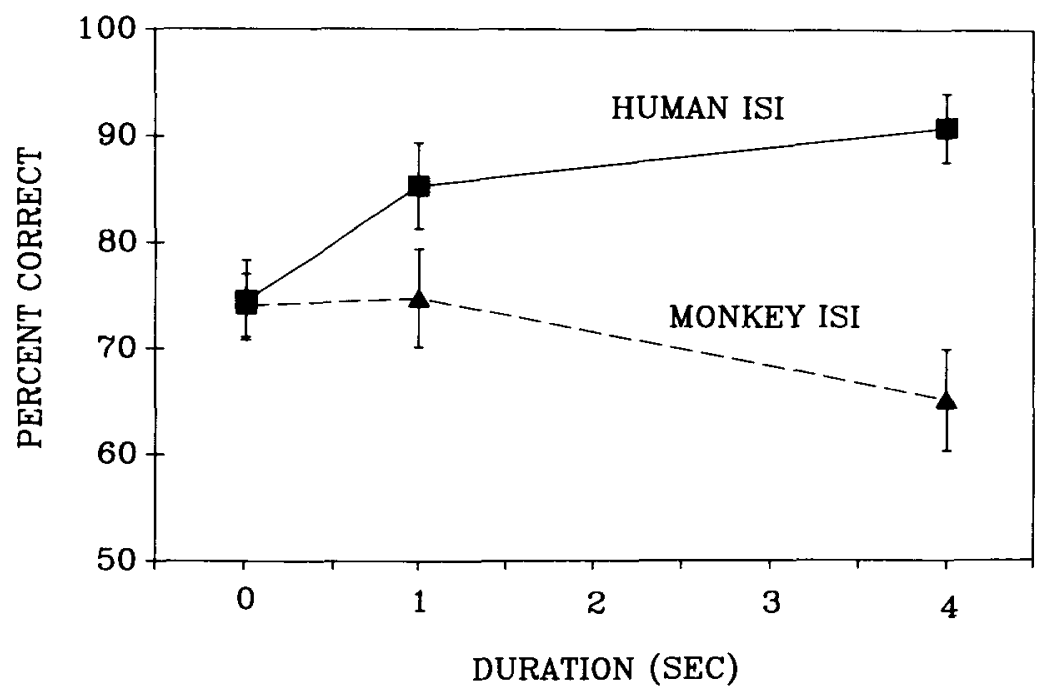

Figure 5. Mean percentage correct for both monkeys from the 6-item list phase and for 9 humans tested with the same procedure by Wright et al. (1990). Error bars represent the standard error of the means. 
portant to note in Figure 5 that for the condition in which viewing time and ISI were both $.08 \mathrm{sec}$, there was no difference in choice accuracy between the monkeys and humans. Such direct human/animal equivalence in almost identical testing conditions is rare, and it establishes a comparable starting point. Hence the subsequent divergence at longer ISIs seems truly to reflect a qualitative processing difference between the species, and it is not a generalized deficit on the part of the monkeys in the specific task. These monkeys can perform as well as human subjects in the SPR task, but only when the requirements for rehearsal are minimal.

The present experiments, along with those of Roberts and Kraemer (1984) and Sands et al. (1984), represent a substantial effort in a search for poststimulus rehearsal mechanisms in nonhuman primates. What is increasingly clear is that in these memory-testing situations in which humans spontaneously rehearse, monkeys do not. Each attempt to identify rehearsal mechanisms in monkeys has resulted in outcomes that are qualitatively different from those obtained with humans. Several conclusions could follow from such results: (1) Monkeys may be incapable of rehearsing; (2) they may have to be instructed or prompted as to when or how to rehearse (frequently true for humans and a potentially important factor); or (3) they may not rehearse information in this context, but might do so in more natural contexts, such as social, sexual, or aggressive encounters. It is possible that the representational processes of the monkeys are specifically attuned to the processing of specific aspects of their environment, such as the social behavior of other monkeys (Cheney \& Seyfarth, 1985). Thus, sexual or aggressive encounters might promote rehearsal in a way in which our nonsocial pictorial stimuli did not. Although such possibilities remain to be examined, at the moment, the evidence suggests that rehearsal-like processes are absent in monkeys.

Implications for theories of memory and the primacy effect. Considerable evidence indicates the existence of two (or possibly more) different human memory processes. One process appears to be associated with primary memory or items contributing to the recency effect, and the other with secondary memory or the prerecency items contributing to the primacy effect (see, e.g., Crowder, 1976; Glanzer, 1972; Tulving, 1985). Interest in this process separation appears to be growing (see, e.g., Sherry \& Schacter, 1987; Squire, 1987; Tulving, 1987; Weiskrantz, 1987).

Many animals also appear to have dual memory processes. A similar division for animals is encouraged by several pieces of evidence. The first is the U-shaped serial position functions for apes (Buchanan, Gill, \& Braggio, 1981), monkeys (Sands \& Wright, 1980a, 1980b; Roberts \& Kraemer, 1981; Wright et al., 1984; Wright et al., 1985), pigeons (Santiago \& Wright, 1984; Wright et al., 1985), and rats (Bolhuis \& van Kampen, 1988; Kesner \& Novak, 1982) in list memory tasks. The second is the selective removal of the primacy effect by hippocampal lesions (Kesner, 1985; Kesner \& Novak, 1982). The third is the differential effect of retention interval manipulations on primacy and recency effects that are qualitatively similar in pigeons, monkeys, and humans (Wright et al., 1985; cf. Tulving, 1987). Finally, there is similar secondary-memory locus for build up and release from proactive interference effects for rhesus monkeys (Jitsumori et al., 1989) and humans (Craik \& Birtwistle, 1971; Stern, 1985; Wickens, Moody, \& Dow, 1981).

In several theories, it has been hypothesized that rehearsal is the critical mechanism that connects these two memory processes (Atkinson \& Shiffrin, 1968; Waugh \& Norman, 1965). Rehearsal transfers items from a limited capacity short-term store to a long-term store. According to these theories, the additional rehearsal that is possible for the initial items of a list produces the primacy effect in the serial position function of list memory tasks (Rundus, 1971; Rundus \& Atkinson, 1970).

Yet although it is clear that rehearsal improves memory in humans, the present experiments and a related set of experiments (Wright et al., 1990) offer a strong case against rehearsal's being a necessary condition for the production of the primacy effect. First, the monkeys showed no evidence of rehearsal, as measured by accuracy changes with ISI, yet some of the serial position functions showed primacy effects. In other experiments with monkeys, very clear primacy effects have been found in testing situations similar to those reported in this article (Roberts \& Kraemer, 1981; Sands \& Wright, 1980a, $1980 \mathrm{~b}$; Wright et al., 1985). The high similarity between the various procedures reduces the likelihood that rehearsal was present in those experiments either. Furthermore, a companion series of experiments in which Wright et al. (1990) examined the relation between ISI and human rehearsal yielded prominent primacy effects in several conditions with humans, but they also yielded no statistical effects of ISI and no evidence of rehearsal when subjects were subsequently interviewed. Such evidence suggests that rehearsal is not a necessary condition for the production of the primacy effect. Of course, such a conclusion still leaves unanswered the question of what produces the primacy effect.

In summary, the results of many recent experiments suggest that the visual working memory processes in humans and monkeys share many common properties and, by implication, common mechanisms (Herzog et al., 1977; Jitsumori et al., 1989; Roberts \& Kraemer, 1981, 1984; Sands \& Wright, 1980a, 1980b, 1982; Wright et al., 1985). The results of the present experiments differ from this, now almost typical, pattern. When tested in conditions designed to detect the use of rehearsal-like mechanisms, the monkeys consistently produced results different from those obtained with humans. If these differences in the effects of ISI accurately reflect the nature of poststimulus rehearsal processes in monkeys and humans, they 
represent an important qualitative difference between the visual working memory mechanisms of the two species.

\section{REFERENCES}

Atkinson, R. C., \& SHiffrin, R. M. (1968). Human memory: A proposed system and its control processes. In K. W. Spence \& J. T. Spence (Eds.), The psychology of leaming and motivation (Vol. 2, pp. 89-105). New York: Academic Press.

Avons, S. E., \& PHLlips, W. A. (1980). Visualization and memorization as a function of display time and poststimulus processing time. Journal of Experimental Psychology: Human Learning \& Memory, 6, 407-420.

Bolhuis, J. J., \& VAN KAMPEN, H. S. (1988). Serial position curves in spatial memory of rats: Primacy and recency effects. Quarterly Journal of Experimental Psychology, 40, 135-149.

Buchanan, J. P., Gill, T. V., \& Braggio, J. T. (1981). Serial position and clustering effects in a chimpanzee's "free recall." Memory \& Cognition, 9, 651-660.

Cheney, D. L., Seyfarth, R. M. (1985). Social and non-social knowledge in vervet monkeys. In L. Weiskrantz (Ed.), Animal intelligence (pp. 187-202). Oxford, U.K.: Clarendon Press.

Craik, F. I. M., \& BirTwistle, J. (1971). Proactive inhibition in free recall. Journal of Experimental Psychology, 91, 120-123.

Crowder, R. G. (1976). Principles of leaming and memory. Hillsdale, NJ: Erlbaum.

DARK, V. J., \& LofTus, G. R. (1976). The role of rehearsal in longterm memory performance. Journal of Verbal Learning \& Verbal Behavior, 15, 479-490.

GlaNZER, M. (1972). Storage mechanisms in recall. In G. H. Bower (Ed.), The psychology of leaming and motivation (Vol. 5, pp. 129-193). New York: Academic Press.

Graefe, T. M., Watkins, M. J. (1980). Picture rehearsal: An effect of selectively attending to pictures no longer in view. Journal of Experimental Psychology: Human Leaming \& Memory, 6, 156-162.

HerzoG, H. L., Grant, D. S., \& RoberTs, W. A. (1977). Effects of sample duration and spaced repetition upon delayed matching-to-sample in monkeys (Macaca arctoides and Saimiri sciureus). Animal Learning \& Behavior, 5, 347-354.

HiNES, D., SMITH, S. (1977). Recognition of random shapes followed at varying delays by attended or unattended shapes, digits, and line grids. Joumal of Experimental Psychology: Human Learning \& Memory, 3, 29-36.

INTRAUB, H. (1980). Presentation rate and the representation of briefly glimpsed pictures in memory. Joumal of Experimental Psychology: Human Learning \& Memory, 6, 1-12.

Jitsumori, M., Wright, A. A., \& Shyan, M. R. (1989). Buildup and release from proactive interference in a rhesus monkey. Journal of Experimental Psychology: Animal Behavior Processes, 15, 329-337.

Johnson, R. E. (1980). Memory-based rehearsal. In G. H. Bower (Ed.), The psychology of learning and motivation (Vol. 14, pp. 263-307). New York: Academic Press.

KePpel, G. (1973). Design and analysis. Englewood Cliffs, NJ: Prentice-Hall.

KESNER, R. P. (1985). Correspondence between humans and animals in coding of temporal attributes: Role of hippocampus and prefrontal cortex. Annals of the New York Academy of Sciences, 44, 122-136.

KeSNER, R. P., \& NovaK, J. M. (1982). Serial position curve in rats: Role of the dorsal hippocampus. Science, 218, 173-175.

Lichtenstern, E. M., KEREN, G. (1979). Effects of perception versus imagery on later recognition of visual patterns. Acta Psychologica, 43, 145-155.

LUTZ, W. J., \& SCHEIRER, C. J. (1974). Coding processes for pictures and words. Joumal of Verbal Learning \& Verbal Behavior, 13, 316-320.

Modigliani, V., HedGes, D. G. (1987). Distributed rehearsals and the primacy effect in single-trial free recall. Journal of Experimental Psychology: Learning, Memory, \& Cognition, 13, 426-436.
Overman, W. H., JR., \& DotY, R. W. (1980). Prolonged visual memory in macaques and man. Neuroscience, $5,1825-1831$.

Phillirs, W. A., \& Christie, D. F. M. (1977). Components of visual memory. Quarterly Joumal of Experimental Psychology, 29, 117-133.

Proctor, R. W. (1983). Recognition memory for pictures as a function of poststimulus interval: An empirical clarification of existing literature. Journal of Experimental Psychology: Learning, Memory, \& Cognition, 9, 256-262.

Proctor, R. W. (1985). How flexible is picture rehearsal? Discussion of Watkins' comment. Journal of Experimental Psychology: Learming, Memory, \& Cognition, 11, 825-828.

ROBERTS, W. A., \& KRAEMER, P. J. (1981). Recognition memory for lists of visual stimuli in monkeys and humans. Animal Learning \& Behavior, 9, 587-594.

Roberts, W. A., Kraemer, P. J. (1984). Picture memory in monkeys. Canadian Journal of Psychology, 38, 218-236.

Rundus, D. (1971). Analysis of rehearsal processes in free recall. Journal of Experimental Psychology, 89, 63-77.

Rundus, D., \& Atkinson, R. C. (1970). Rehearsal processes in free recall: A procedure for direct observation. Joumal of Verbal Learning \& Verbal Behavior, 9, 99-105.

Sands, S. F., Urculoli, P. J., Wright, A. A., \& Santiago, H. C. (1984). Serial position effects and rehearsal in primate visual memory. In H. L. Roitblat, T. G. Bever, \& H. S. Terrace (Eds.), Animal cognition (pp. 375-388). Hillsdale, NJ: Erlbaum.

SANDS, S. F., WRIGHT, A. A. (1980a). Primate memory: Retention of serial list items by a rhesus monkey. Science, 209, 938-940.

SANDS, S. F., WRIGHT, A. A. (1980b). Serial probe recognition performance by a rhesus monkey and a human with 10 - and 20 -item lists. Journal of Experimental Psychology: Animal Behavior Processes, 6, 386-396.

SANDS, S. F., \& WRIGHT, A. A. (1982). Monkey and human pictorial memory scanning. Science, 216, 1333-1334.

Santiago, H. C., \& Wight, A. A. (1984). Pigeon memory: Same/ different concept learning, serial probe recognition acquisition and probe delay effects in the serial position function. Journal of $E x-$ perimental Psychology: Animal Behavior Processes, 10, 498-512.

SHAFFE, W. O., \& SHIFrin, R. M. (1972). Rehearsal and storage of visual information. Joumal of Experimental Psychology, 92, 292-296.

SherRY, D. F., \& SCHacter, D. L. (1987). The evolution of multiple memory systems. Psychological Review, 94, 439-454

SQuire, L. R. (1987). Memory and brain. New York: Oxford University Press.

STERN, L. (1985). The structures and strategies of human memory. Homewood, IL: Dorsey Press.

Tulving, E. (1985). How many memory systems are there? American Journal of Psychology, 40, 385-398.

Tulving, E. (1987). Introduction: Multiple memory systems and consciousness. Human Neurobiology, 6, 67-80.

Tversky, B., \& Sherman, B. (1975). Picture memory improves with longer on time and off time. Journal of Experimental Psychology: Human Learning \& Memory, 1, 114-118.

WATkINS, J. M. (1985). Strategies of picture rehearsal: A comment on Proctor's (1983) article. Joumal of Experimental Psychology: Human Learning \& Memory, 11, 821-824.

WATKINS, M. J., \& GRAEFE, T. M. (1981). Delayed rehearsal of pictures. Journal of Verbal Learning \& Verbal Behavior, 20, 276-288.

Watkins, J. M., \& PeYnircioglu, Z. F. (1982). A perspective on rehearsal. In G. H. Bower (Ed.), The psychology of learning and motivation (Vol. 16, pp. 153-190). New York: Academic Press.

Watkins, J. M., Peynircioglu, Z. F., \& Brems, D. J. (1984). Pictorial rehearsal. Memory \& Cognition, 12, 553-557.

Waugh, N. C., Norman, D. A. (1965). Primary memory. Psychological Review, 72, 89-104.

Weaver, G. E. (1974). Effects of poststimulus study time on recognition of pictures. Journal of Experimental Psychology, 103, 799-801.

Weaver, G. E., StanNy, C. J. (1978). Short-term retention of pictorial stimuli as assessed by a probe recognition technique. Journal of Experimental Psychology: Human Learning \& Memory, 4, 55-65. 
Weiskrantz, L. (1987). Neuroanatomy of memory and amnesia: A case for multiple memory systems. Human Neurobiology, 6, 93-105. WickeNs, D. D., Moody, M. J., \& Dow, R. (1981). The nature and timing of the retrieval process and of interference effects. Journal of Experimental Psychology: General, 110, 1-20.

Wright, A. A., COOK, R. G., Kendrick, D. F. (1989). Relational and absolute stimulus learning by monkeys in a memory task. Journal of the Experimental Analysis of Behavior, 52, 237-248.

Wright, A. A., CoOk, R. G., Rivera, J. J., Shyan, M. R., Neiworth, J. J., \& Jirsumor, M. (1990). Naming, rehearsal, and interstimulus interval effects in memory processing. Journal of Experimental Psychology: Learning, Memory, \& Cognition, 16, 1043-1059.

Wright, A. A., Santiago, H. C., Sands, S. F. (1984). Monkey memory: Same/different concept learning, serial probe acquisition, and probe delay effects. Journal of Experimental Psychology: Animal Behavior Processes, 10, 513-529.
Wright, A. A., Santiago, H. C., Sands, S. F., Kendrick, D. F., \& Cook, R. G. (1985). Memory processing of serial lists by pigeons, monkeys, and people. Science, 229, 287-289.

Wright, A. A., Urculoli, P. J., Sands, S. F. (1986). Proactive interference in animal memory research. In D. F. Kendrick, M. Rilling, \& R. Denny (Eds.), Theories of animal memory (pp. 101-125). Hillsdale, NJ: Erlbaum.

\section{NOTES}

1. These values are transformations of those reported by Intraub (1980), making them comparable to those reported in this article.

(Manuscript received June 8, 1990; revision accepted for publication November 19, 1990.) 